\title{
Transient bending analysis of a functionally graded circular plate with integrated surface piezoelectric layers
}

\author{
Ali Asghar Jafari ${ }^{1}$, Ali Akbar Jandaghian ${ }^{2}$ and Omid Rahmani ${ }^{2 *}$
}

\begin{abstract}
Background: Thin and piezoelectric materials are widely used as sensors or actuators in smart structures by embedding or surface-mounted them.

Methods: This paper report on the exact, explicit solution for the transient bending of a circular functionally graded (FG) plates integrated with two uniformly distributed actuator layers made of piezoelectric material based on the classical plate theory (CPT). The material properties of the FG substrate plate are assumed to be graded in the thickness direction according to the power-law distribution in terms of the volume fractions of the constituents and the distribution of electric potential field along the thickness direction of piezoelectric layers is simulated by a quadratic function. The form of the electric potential field in the piezoelectric layer is considered such that the Maxwell static electricity equation is satisfied. The governing equations are solved for clamped and simply supported edge boundary condition of the circular plate. The solutions are expressed by elementary Bessel functions and derived via exact inverse Laplace transform.
\end{abstract}

Results and Conclusions: It is seen that the power index $(g)$ and thickness of piezo-layer have significant effect on the deflection amplitude and natural frequency of piezo-FG plate.

Keywords: Functionally graded material; Piezoelectric; Transient bending; Elasticity solution

\section{Background}

The active and controllable mechanical properties of piezoelectric materials are extensively recognized as one of the most important resources for the development of intelligent self-monitoring and self-adaptive lightweight structures (Rahmani and Noroozi Moghaddam 2014). Adaptive structures, incorporating piezoelectric patches for sensing and actuation, are now broadly used in the field of active and passive vibration and shape control, in medical instruments, in measuring apparatus, and in micro-electromechanical systems (Jandaghian et al. 2013). A metal substrate surface bonded or embedded by a piezoelectric layer has received considerable attention throughout the last decades for practical designs of sensors and actuators because of the electromechanically coupling characteristics (Jandaghian et al. 2014).

\footnotetext{
* Correspondence: omid.rahmani@znu.ac.ir

${ }^{2}$ Smart Structures and New Advanced Materials Laboratory, Mechanical Engineering Department, University of Zanjan, Zanjan 45371-38791, Iran Full list of author information is available at the end of the article
}

Recently, functionally graded (FG) materials which exhibit smooth variation of material properties (Rahmani and Pedram 2014) have been studied for developing smart FG structures (Rahmani et al. 2010). By utilizing piezoelectric materials as actuators or sensors, smart FG structures have been made with capabilities of selfcontrolling and self-monitoring. The design of devices including active piezoelectric materials requires, as an initial step, an efficient modeling of the electrical, mechanical, and coupling properties of the host structure, the piezoelectric elements, and their interactions. In the following, a review of recent findings and developments in modeling of smart FG structures will be presented. Pan and Han (2005) presented an exact solution for multilayered rectangular plate made of functionally graded, anisotropic, and linear magneto-electro-elastic materials. In this work, the influence of the exponential factor, the magneto-electro-elastic properties, and loading types on induced magneto-electric-elastic fields have been investigated. Batra (Batra and Liang 1997; Vel and Batra 2001) investigated the vibration behavior of a rectangular 
laminated elastic plate with embedded piezoelectric sensors and actuators with a piezoelectric plate subjected to transient thermal loading. Batra and Geng (2002) considered a FG viscoelastic layer but a homogeneous PZT constraining layer and performed the three-dimensional transient analysis of the problem with the finite element method (FEM). He et al. (2001) suggested a finite element formulation based on the classical laminated plate (CLP) theory for the shape and vibration control of the FG material plates with integrated piezoelectric sensors and actuators and used a constant velocity feedback control algorithm for the active control of the dynamic response of the plate through closed-loop control. Reddy and Cheng (2001) studied the bending of a FG rectangular plate with an attached piezoelectric actuator. They have employed the transfer matrix and asymptotic expansion techniques to obtain a three-dimensional asymptotic solution. Bhangale and Ganesan (2006) studied the static behavior of functionally graded, anisotropic, and linear magnetoelectro-elastic plates, using a semi-analytical finite element plate model. In this study, the material constitution was assumed to vary in an exponential way across the thickness direction. A FE formulation was suggested by Liew et al. (2002) for modeling and controlling piezoelectric shell laminates under coupled displacement, temperature, and electric potential fields. The base shell was of FG material type that consists of combined ceramic-metal materials with different mixing ratios of the ceramic and metal constituents. Ray and Sachade (2006) presented a finite element model for the static analysis of FG plates with a layer of piezoelectric fiber reinforced composite material and investigated the effect of varying the fiber angle in the piezoelectric fiber reinforced composite layer on its actuating capability of the functionally graded plates. Ootao and Tanigawa (Ootao and Tanigawa 2000; Tanigawa 2001) studied the FGM simply supported rectangular plate bonded to a piezoelectric material. A study on the nonlinear vibration and dynamic response of a FG material plate with surface-bonded piezoelectric layers in thermal environments was developed by Huang and Shen (2006). The nonlinear formulations were based on the higher-order shear deformation plate theory (HSDT) including thermopiezoelectric effects. In this study, they accounted to heat conduction and temperature-dependent material properties, and a variation through the plate thickness both for the temperature field and for the electrical field intensity was assumed. Wang and Noda (2001) investigated a smart FG composite structure composed of a metal layer, piezoelectric layer, and a FG layer in between.

A study on FG beams with surface-integrated piezoelectric actuators and sensors based on a state space formulation was carried out by Bian et al. (2006). In their study, a spring layer modeled the bonding adhesive between the host beam and the piezoelectric layers in order to consider its effect. The bonding conditions were simulated through the consideration of different spring layer parameters. Free axisymmetric vibration problem of piezoelectric coupled thin circular (Ebrahimi and Rastgo 2008) and thin annular (Ebrahimi and Rastgoo 2008) FGM plates has been carried out by Ebrahimi and Rastgoo. Also, Ebrahimi et al. suggested an analytical solution to the analysis of smart moderately thick shear deformable annular (Ebrahimi et al. 2009) and circular (Ebrahimi et al. 2008) FG plate based on Mindlin's plate theory. Wang et al. (2001) studied free vibration of a circular plate surface bonded by two piezoelectric layers, based on the Kirchhoff theory. They have shown that the mode shape of the electric potential obtained from free vibration analysis is generally to be nonuniform in the radial direction in contrast to what is commonly assumed. Zhang et al. present an exact, explicit solution to study the static and transient bending characteristics of a thin piezoelectric circular plate under electromechanical loading, grounded over the whole surface and built-in or simply supported at the edge (Zhang et al. 2004). A study on the performance of vertically reinforced 1-3 piezoelectric composite distributed actuator in the active constrained layer damping system bonded to a FG plate was carried out by Ray and Batra (2007). They modeled the deformations of each layer by the first-order shear deformation theory. HosseiniHashemi et al. suggested an analytical solution to the investigation and vibration of thick plates. They studied free vibration of piezoelectric coupled thick circular/annular FG plates with different boundary conditions based on Reddy's third-order shear deformation theory (TSDT) (Hosseini Hashemi et al. 2010), thick circular isotropic plate (Hosseini-Hashemi et al. 2010b), and smart Reddy plate (Hosseini-Hashemi et al. 2010a).

In another study, Kargarnovin et al. (2007) investigated the active vibration control of FG material plates using piezoelectric sensor/actuator patches, using CLP theory. In their work, the effect of the feedback gain and the volume fraction on the plate frequency and displacement was studied. Es'haghi et al. (2011) presented an analytical solution for vibration study of piezoelectric coupled FG Mindlin plates which have open-circuit piezoelectric patches and have been used as sensors. Alibeigloo (2010) presented an analytical solution for FG beams integrated with orthotropic piezoelectric actuator and sensor, under an applied electric field and thermomechanical load. Studies on the effect of the grading index, thickness ratio, the electromechanical coupling, and thermo-mechanical surface boundary condition on the bending behavior of the structure were analyzed. Static analysis of functionally graded, transversely isotropic, and magneto-electro-elastic circular plate under uniform mechanical load was discussed by Li et al. (2008). In this investigation, they represented displacements and 
electric potential by appropriate polynomials in the radial coordinate. Shiyekar and Kant (2010) investigated the bidirectional flexure behavior of FG plates with integrated piezoelectric fiber reinforced composites. They considered the HSDT theory to analyze the performance of this plate subjected to electromechanical loadings. The electrostatic potential was assumed as layer-wise linear through the thickness of the piezoelectric layer. Shen (2005) presented a postbuckling analysis for a simply supported and functionally graded plate with piezoelectric actuators subjected to the combined action of mechanical, electrical, and thermal loads. The governing equations in his study were based on a thermo-piezoelectric higher-order shear deformation plate theory. Fakhari et al. (2011) suggested a FE formulation based on the HSDT plate theory to investigate the nonlinear natural frequencies, time, and frequency responses of FG plate with surface-bonded piezoelectric layers under thermal, electrical, and mechanical loads. Numerical results have been presented to study the effects of the volume fraction exponent, the applied voltage in piezoelectric layers, the thermal load, and the vibration amplitude on nonlinear natural frequencies, and time response of the plate with integrated piezoelectric layers was studied. Hashemi et al. (2012) developed an analytical solution for the free vibration of piezoelectric coupled FG thick circular/annular plates on the basis of Mindlin's first-order shear deformation plate theory (FSDT) and studied the effects of coupling between in-plane and transverse displacements on the frequency parameters. Komeili et al. (2011) carried out the bending of problem of beams made of FG piezoelectric materials under a combined thermo-electro-mechanical load. They considered different shear deformation theories to perform a parametric study focused on the evaluation of the effect of the material composition, voltage, end supports, shear deformation, and the slenderness ratio on the thermo-electro-mechanical performance. Loja et al. (2013) studied the static and free vibration behavior of functionally graded sandwich plate-type structures, using B-spline finite strip element models based on different shear deformation theories. Geometrical nonlinear static and free vibration analyses of FG piezoelectric plates using FEM were studied by Behjat and Khoshravan (2012). On their work, different sets of mechanical and electrical loadings were considered. The plate with FG piezoelectric material was considered to vary gradually through the thickness by a power law distribution. The electric potential was assumed to vary in a quadratic way through the thickness and was considered to be a nodal degree of freedom. Liew et al. (2003) presented a FE model for the static and dynamic piezothermoelastic analysis and control of FGM plates under temperature gradient environments using integrated piezoelectric sensor/actuator layers. They also applied a feedback control algorithm that couples the direct and inverse piezoelectric effects to provide active control of the integrated FGM plate in a closed-loop system.

To the best knowledge of authors and from carried out literature review, there are no studies on the transient motion of FG circular plate integrated with piezoelectric material. In this work, the transient bending of a thin, circular FGM plate integrated with piezoelectric layers under axisymmetric mechanical loading is presented for different boundary conditions. The piezoelectric layers are electrically grounded over the edge, and electrodes at the two surfaces of the piezoelectric layers are shortly connected. The properties of the substrate plates were graded in the thickness direction according to a volume fraction power law distribution. A consistent formulation based on the classical plate theory that satisfies the Maxwell static electricity equation is proposed for the piezoelectric layers. The distribution of electric potential field in the thickness direction of the piezoelectric layers is simulated by a quadratic function, and the solutions are presented in terms of a single, elementary Bessel function. In the following, the explicit time history of the solution is achieved by precise inverse Laplace transformation. Consequently, accurate results of system characteristics can simply be acquired applying straightforward numerical process.

\section{Methods}

The effective material properties of the FG plate are assumed to vary through the thickness of the plate. The property variation is assumed to be in terms of a simple power law distribution which can be expressed by

$$
P=\left(P_{c}-P_{m}\right)\left(\frac{2 z+h}{2 h}\right)^{g}+P_{m}
$$

From the above equation, the effective Young's modulus $E$ and shear modulus $G$ can be determined as

$$
\begin{aligned}
& E(z)=\left(E_{c}-E_{m}\right)\left(\frac{z}{2 h}+\frac{1}{2}\right)^{g}+E_{m} \\
& G(z)=\left(G_{c}-G_{m}\right)\left(\frac{z}{2 h}+\frac{1}{2}\right)^{g}+G_{m}
\end{aligned}
$$

Also, Poisson's ratio $v$ is assumed to be constant, and the density $\rho$ change in the thickness direction $z$ will be

$$
\rho(z)=\left(\rho_{c}-\rho_{m}\right)\left(\frac{z}{2 h}+\frac{1}{2}\right)^{g}+\rho_{m},
$$

where subscripts ' $m$ ' and 'c' refer to the metal and ceramic constituents, respectively.

Consider a three-layer circular plate, including one host FG layer in the middle and two identical piezoelectric 


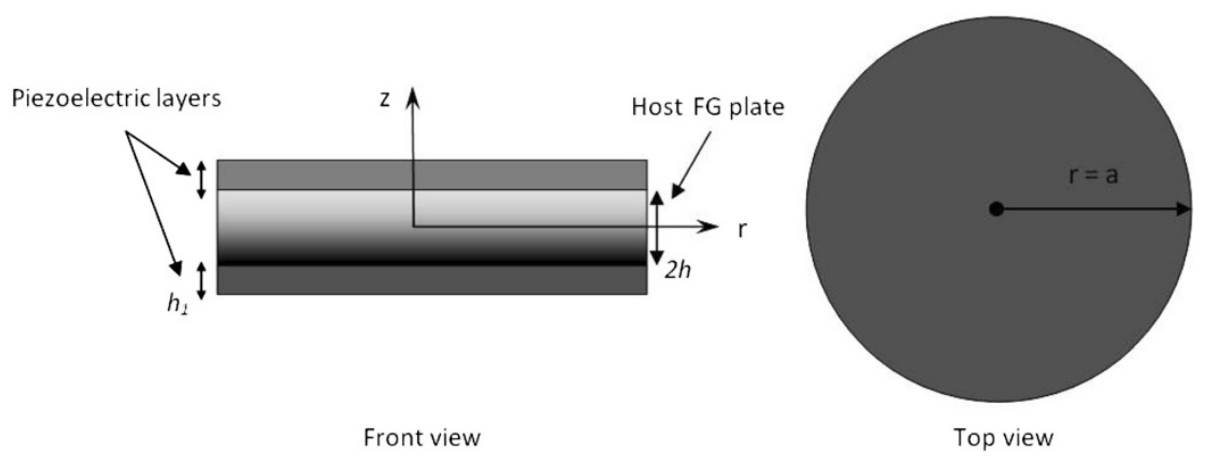

Figure 1 Geometry of circular FG plate with two piezoelectric layers mounted on its surfaces.

layers bonded perfectly to the upper and lower surfaces of the host layer, with outer radius $a$, host plate thickness $2 h$, and piezoelectric layer thickness $h_{1}$, as depicted in Figure 1.

In this study, according to the ratio of the plate radius to its thickness, the Kirchhoff assumption for thin plates is applicable, whereby the shear deformation and rotary inertia can be omitted. In addition, the axisymmetric applied external load is assumed.

According to symmetry, the displacement and strains in the circular plate are considered as (Ebrahimi and Rastgo 2008)

$$
\begin{aligned}
& u_{z}(r, t)=w(r, t) \\
& u_{r}(r, t)=-z \frac{\partial u_{z}}{\partial r} \\
& u_{\theta}(r, t)=0
\end{aligned}
$$

Where $u_{z}, u_{n}$ and $u_{\theta}$ are the displacements in the transverse $z$ direction, radial $r$ direction, and tangential $\theta$ direction of the plate, respectively. The poling direction of the piezoelectric material is considered to be in the $z$ direction. The strain $\varepsilon$ in the FG plate and the piezoelectric layer with respect to the radial and tangential directions and the shear component are given by

$$
\begin{aligned}
& \varepsilon_{r}=-z \frac{\partial^{2} w}{\partial r^{2}} \\
& \varepsilon_{\theta}=-z \frac{\partial w}{r \partial r} \\
& \varepsilon_{r \theta}=0
\end{aligned}
$$

The stress components in the FG circular plate are adopted as (Timoshenko et al. 1959)

$$
\sigma_{r}^{1}=\frac{E(z)\left(\varepsilon_{r}+\nu \varepsilon_{\theta}\right)}{1-v^{2}}
$$

$$
\sigma_{\theta}^{1}=\frac{E(z)\left(\varepsilon_{\theta}+v \varepsilon_{r}\right)}{1-v^{2}}
$$

By substituting Equations 8 and 9 into Equations 11 and 12 ,

$$
\begin{aligned}
& \sigma_{r}^{1}=\frac{-z E(z)}{1-v^{2}}\left[\frac{\partial^{2} w}{\partial r^{2}}+\frac{v}{r} \frac{\partial w}{\partial r}\right] \\
& \sigma_{\theta}^{1}=\frac{-z E(z)}{1-v^{2}}\left[\frac{1}{r} \frac{\partial w}{\partial r}+v \frac{\partial^{2} w}{\partial r^{2}}\right] \\
& \tau_{r \theta}=0
\end{aligned}
$$

The stress components in the piezoelectric layer can be expressed as (Timoshenko et al. 1959)

$$
\begin{aligned}
\sigma_{r}^{2} & =C_{11}^{E} \varepsilon_{r}+C_{12}^{E} \varepsilon_{\theta}+C_{13}^{E} \varepsilon_{z}-e_{31} E_{z} \\
\sigma_{\theta}^{2} & =C_{12}^{E} \varepsilon_{r}+C_{11}^{E} \varepsilon_{\theta}+C_{13}^{E} \varepsilon_{z}-e_{31} E_{z} \\
\sigma_{z}^{2} & =C_{13}^{E} \varepsilon_{r}+C_{13}^{E} \varepsilon_{\theta}+C_{33}^{E} \varepsilon_{z}-e_{33} E_{z}
\end{aligned}
$$

For thin plate theory $\sigma_{z}^{2}=0$, so $\varepsilon_{z}$ in the plane stress condition is derived from Equation 18:

$$
\varepsilon_{z}=\frac{e_{33} E_{z}-C_{13}\left(\varepsilon_{r}+\varepsilon_{\theta}\right)}{C_{33}}
$$

Substituting Equation 19 into Equations 16 and 17 gives

$$
\begin{aligned}
& \sigma_{r}^{2}=\bar{C}_{11}^{E} \varepsilon_{r}+\bar{C}_{12}^{E} \varepsilon_{\theta}-\bar{e}_{31} E_{z} \\
& \sigma_{\theta}^{2}=\bar{C}_{12}^{E} \varepsilon_{r}+\bar{C}_{11}^{E} \varepsilon_{\theta}-\bar{e}_{31} E_{z}
\end{aligned}
$$

where the superscripts 1 and 2 refer to the variables in the FG structure and the piezoelectric material, respectively. $e_{31}$ and $e_{33}$ are the piezoelectric constants of the piezoelectric layer. $\bar{C}_{11}^{E}, \bar{C}_{12}^{E}$ and $\bar{e}_{31}$ are transformed reduced material constants of piezoelectric medium for the plane stress problem and are expressed by (Wang et al. 2001) 


$$
\begin{aligned}
& \bar{C}_{11}^{E}=C_{11}^{E}-\frac{\left(C_{13}^{E}\right)^{2}}{C_{33}^{E}} \\
& \bar{C}_{12}^{E}=C_{12}^{E}-\frac{\left(C_{13}^{E}\right)^{2}}{C_{33}^{E}} \\
& \bar{e}_{31}=e_{31}-\frac{C_{13}^{E}}{C_{33}^{E}} e_{33}
\end{aligned}
$$

$C_{11}^{E}, C_{12}^{E}$ and $C_{33}^{E}$ are the elastic modulus of the piezoelectric material in the radial and tangential directions, measured at constant electric field; two piezoelectric layers are bonded to the FG plate and are proposed to be used as an actuator or sensor. There are a number of models representing the input electric potential for such a piezoelectric layer. In this study, we adopt the following potential function (Wang et al. 2001):

$$
\phi(r, z, t)=\left[1-\left(\frac{2 z-2 h-h_{1}}{h_{1}}\right)^{2}\right] \phi(r, t),
$$

where $z$ is measured from the mid-plane of the plate in the global $\mathrm{z}$ direction, $h_{1}$ is the thickness of the piezoelectric layer, and $\phi(r, t)$ is the electric potential on the mid-surface of the piezoelectric layer, and the electrodes on each piezoelectric layer are short circuit.

On the basis of Equation 25, the components of the electric field intensity $E$ and electric flux density $D$ are expressed as (Wang et al. 2001)

$$
\begin{aligned}
E_{r} & =-\frac{\partial \phi}{\partial r}=\left[1-\left(\frac{2 z-2 h-h_{1}}{h_{1}}\right)^{2}\right] \frac{\partial \phi}{\partial r} \\
E_{\theta} & =-\frac{\partial \phi}{\partial \theta}=0 \\
E_{z} & =-\frac{\partial \phi}{\partial z}=\frac{8\left(z-h-h_{1} / 2\right)}{h_{1}^{2}} \phi \\
D_{r} & =\bar{\Xi}_{11} E_{r}=-\bar{\Xi}_{11}\left[1-\left(\frac{2 z-2 h-h_{1}^{2}}{h_{1}}\right)^{2}\right] \frac{\partial \phi}{\partial r} \\
D_{\theta} & =\bar{\Xi}_{11} E_{\theta}=0 \\
D_{z} & =\bar{\Xi}_{33} E_{z}+\bar{e}_{31}\left(\varepsilon_{r}+\varepsilon_{\theta}\right) \\
& =\frac{8 \bar{\Xi}_{33}\left(z-h-h_{1} / 2\right)}{h_{1}^{2}} \phi+\bar{e}_{31}^{2} z \nabla^{2} w,
\end{aligned}
$$

where $\bar{\Xi}_{11}$ and $\bar{\Xi}_{33}$ are reduced dielectric constants of the piezoelectric layer in the plane stress condition, which are expressed by $\bar{\Xi}_{11}=\Xi_{11}, \bar{\Xi}_{33}=\Xi_{33}+\left(e_{33}^{2} / C_{33}^{E}\right)$. $E_{n}$ $E_{\theta}$, and $E_{z}$ are the electric field intensities in the $r, \theta$, and $z$ directions, respectively; $D_{n} D_{\theta}$, and $D_{z}$ are the related electric displacements. $\Xi_{11}$ and $\Xi_{33}$ are the dielectric constants of the piezoelectric layer; $\nabla^{2}$ is the Laplace operator and expressed by

$$
\nabla^{2}=\frac{\partial^{2}}{\partial r^{2}}+\frac{1}{r} \frac{\partial}{\partial r}
$$

\section{Equilibrium equations}

To achieve the equilibrium differential equation of the coupled circular plate, resultant moments obtained as (Timoshenko et al. 1959)

$$
\begin{aligned}
M_{r} & =\int_{-h-h_{1}}^{h+h_{1}} z \sigma_{r} d z=\int_{-h}^{h} z \sigma_{r}^{1} d z+2 \int_{h}^{h+h_{1}} z \sigma_{r}^{2} d z \\
& =-\left[\left(D_{1}+D_{2}\right) \frac{\partial^{2} w}{\partial r^{2}}+\left(v D_{1}+\frac{\bar{C}_{12}^{E}}{\bar{C}_{11}^{E}} D_{2}\right) \frac{\partial w}{r \partial r}+\frac{4}{3} h_{1} \bar{e}_{31} \phi\right] \\
M_{\theta} & =\int_{-h-h_{1}}^{h+h_{1}} z \sigma_{\theta} d z=\int_{-h}^{h} z \sigma_{\theta}^{1} d z+2 \int_{h}^{h+h_{1}} z \sigma_{\theta}^{2} d z \\
& =-\left[\left(v D_{1}+\frac{\bar{C}_{12}^{E}}{\bar{C}_{11}^{E}} D_{2}\right) \frac{\partial^{2} w}{\partial r^{2}}+\left(D_{1}+D_{2}\right) \frac{\partial w}{r \partial r}+\frac{4}{3} h_{1} \bar{e}_{31} \phi\right]
\end{aligned}
$$

and the resultant shear force is given by

$$
Q_{r}=\frac{\partial M_{r}}{\partial r}+\frac{M_{r}-M_{\theta}}{r},
$$

where the thickness of the FG plate is $2 h$; the piezoelectric layer extends from $z=h$ to $z=h+h_{1}$.

Substituting Equation 32 into Equations 33 and 34 and substituting the final results into the governing equation for the Kirchhoff circular plate,

$$
\frac{\partial Q_{r}}{\partial r}+\frac{Q_{r}}{r}-\left(\int_{-h}^{h} \rho_{1}(z) \frac{\partial^{2} u_{z}}{\partial t^{2}} d z+2 \int_{h}^{h+h_{1}} \rho_{2} \frac{\partial^{2} u_{z}}{\partial t^{2}}\right)+f=0,
$$

where $\rho_{1}(z)$ and $\rho_{2}$ are densities of the FG plate and piezoelectric layer, respectively, and $f=f(r, t)$ is the external load.

In the following, the piezoelectric coupled circular FGM plate equation is derived as:

$$
\begin{gathered}
\left(D_{1}+D_{2}\right) \nabla^{4} w(r, t)+\frac{4}{3} h_{1} \bar{e}_{31} \nabla^{2} \phi(r, t) \\
+2\left(\bar{\rho} h+\rho_{2} h_{1}\right) \frac{\partial^{2} w(r, t)}{\partial t^{2}}=f(r, t),
\end{gathered}
$$


where

$$
D_{1}=\int_{-h}^{h} \frac{z^{2} E(z)}{1-v^{2}} d z, \quad D_{2}=\frac{2}{3} h_{1}\left(3 h^{2}+3 h h_{1}+h_{1}^{2}\right) C_{11}^{E}
$$

and $\bar{\rho}=\frac{1}{2 h} \int_{-h}^{h} \rho_{1}(z) d z$.

Note that all of the electrical variables primarily must satisfy Maxwell's equation, which requires that the divergence of the electric flux density vanishes at any point within the media as (Timoshenko et al. 1959)

$$
\int_{h}^{h+h_{1}}\left(\frac{\partial D_{r}}{\partial r}+\frac{D_{r}}{r}+\frac{\partial D_{z}}{\partial z} d z\right) d z=0 .
$$

Substituting Equations 29 and 31 into Equation 37 yields

$$
\frac{h_{1}^{2} \bar{\Xi}_{11}}{12 \bar{\Xi}_{33}} \nabla^{2} \phi(r, t)-\phi(r, t)+\frac{h_{1}^{2} \bar{e}_{31}^{2}}{8 \bar{\Xi}_{33}} \nabla^{2} w(r, t)=0 .
$$

In the next section, the solution of two coupled partial differential Equations 36 and 38 will be discussed according to the following mechanical and electrical boundary conditions and symmetry constraints for the simply supported and fully grounded piezoelectric coupled FG plate.

\section{Analytical solution procedure}

The results of transient bending analysis are given below for two boundary conditions, corresponding to the simply supported and clamped circular plate.

\section{Simply supported circular plate}

The initial conditions and boundary conditions are

$$
\begin{aligned}
& t=0: w=\dot{w}=\phi=\dot{\phi}=0 . \\
& r=a: w=M_{r}=\phi=0, z= \pm h: \\
& \phi=0, z= \pm\left(h+h_{1}\right): \phi=0,
\end{aligned}
$$

where, in Equation 39, $\dot{w}=\frac{\partial w}{\partial t}$ and $\dot{\phi}=\frac{\partial \phi}{\partial t}$.

For the external load $f(r, t)$ in Equation 36, we consider

$$
f(r, t)=F(r) H(t),
$$

where $F(r)$ is given, and $H(t)$ is the Heaviside step function.

Introducing the Laplace transforms

$$
\begin{aligned}
w^{*}(r, s) & =\int_{0}^{\infty} w(r, t) e^{-s t} d t \text { and } \phi^{*}(r, s) \\
& =\int_{0}^{\infty} \phi(r, t) e^{-s t} d t
\end{aligned}
$$

and taking the Laplace transform of Equations 36 and 38 yields

$$
\begin{aligned}
& \left(D_{1}+D_{2}\right) \nabla^{4} w^{*}(r, s)+\frac{4}{3} h_{1} \bar{e}_{31} \nabla^{2} \phi^{*}(r, s) \\
& \quad+2\left(\bar{\rho} h+\rho_{2} h_{1}\right) s^{2} w^{*}(r, s)=\frac{F(r)}{s} \\
& \frac{h_{1}^{2} \bar{\Xi}_{11}}{12 \bar{\Xi}_{33}} \nabla^{2} \phi^{*}(r, s)-\phi^{*}(r, s)+\frac{h_{1}^{2} \bar{e}_{31}^{2}}{8 \bar{\Xi}_{33}} \nabla^{2} w^{*}(r, s)=0 .
\end{aligned}
$$

According to Equation 32,

$$
M_{r}=-\left[\left(D_{1}+D_{2}\right) \frac{\partial^{2} w}{\partial r^{2}}+\left(v D_{1}+\frac{\bar{C}_{12}}{\bar{C}_{11}} D_{2}\right) \frac{1}{r} \frac{\partial w}{\partial r}+\frac{4}{3} h_{1} \bar{e}_{31} \phi\right]
$$

According to (Rao 2007), to simplify the solution, the boundary condition of Equation 35 is assumed approximately as (Sneddon 1995)

$$
M_{r}=-\left[\left(D_{1}+D_{2}\right)\left(\frac{\partial^{2} w}{\partial r^{2}}+\frac{1}{r} \frac{\partial w}{\partial r}\right)+\frac{4}{3} h_{1} \bar{e}_{31} \phi\right]
$$

The transient solution is written in terms of Bessel function, so we consider

$$
\begin{aligned}
w^{*}(r, s) & =\sum_{j=1}^{\infty} A_{j}(s) J_{0}\left(\alpha_{j} r\right) \\
\phi^{*}(r, s) & =\sum_{j=1}^{\infty} B_{j}(s) J_{0}\left(\alpha_{j} r\right)
\end{aligned}
$$

$A_{j}(s)$ and $B_{j}(s)$ are unknown functions and should be determined. Moreover, $F(r)$ is expanded into a series in terms of Bessel functions, as

$$
\begin{aligned}
F(r) & =q_{1} J_{0}\left(\alpha_{1} r\right)+q_{2} J_{0}\left(\alpha_{2} r\right)+\ldots, \\
& =\sum_{j=1}^{\infty} q_{j} J_{0}\left(\alpha_{j} r\right)
\end{aligned}
$$

where $q_{j}$ can be determined by orthogonality of Bessel functions as follows:

$$
q_{j}=\frac{2}{a^{2}} \frac{1}{J_{1}^{2}\left(\alpha_{j} a\right)} \int_{0}^{a} r q(r) J_{0}\left(\alpha_{j} r\right) d r, j=1,2, \ldots
$$

In Equations 47, 48, and 50, $J_{0}(\alpha r)$ and $J_{1}(\alpha r)$ are Bessel functions of first kind of order zero and one, respectively (Abramowitz and Stegun 1964), and $\alpha_{j}$ are the positive roots of

$$
J_{0}(\alpha a)=0 .
$$


It should be noted that the solutions $w^{*}(r)$ and $\phi^{*}(r)$ in Equations 47 and 48 satisfy Equations 43 and 44 and all initial and boundary conditions in the problem.

Substituting Equations 47 and 48 into Equation (44) gives

$$
B_{j}(s)=\frac{-p_{0} \alpha_{j}^{2}}{1+p_{1} \alpha_{j}^{2}} A_{j}(s)
$$

Substituting Equations 47, 48, 49, and 53 into Equation 43 gives

$$
A_{j}(s)=\frac{q_{j}}{s D\left(\alpha_{j}^{4}+\lambda s^{2}+C_{j}\right)}
$$

where $D=D_{1}+D_{2}$, and

$$
\begin{aligned}
p_{0} & =\frac{4 h_{1} \bar{e}_{31}}{3 D}, p_{1}=\frac{h_{1}^{2} \bar{\Xi}_{11}}{12 \bar{\Xi}_{33}}, p 2=\frac{h_{1}^{2} \bar{e}_{31}}{8 \Xi_{33}} \lambda \\
& =\frac{2\left(\bar{\rho} h+\rho_{2} h_{1}\right)}{D}, \quad C_{j}=\frac{p_{0} \alpha_{j}^{4}}{1+p_{1} \alpha_{j}^{2}}
\end{aligned}
$$

Assuming $a_{j}=\sqrt{\frac{\alpha_{j}^{4}+C_{j}}{\lambda}}$, consequently,

$$
A_{j}(s)=\frac{q_{j}}{s D\left(s^{2}+a_{j}^{2}\right)}
$$

The inverse Laplace transform is applied to $w^{*}(r, s)$ and $\phi^{*}(r, s)$ to derive the final solution in the time domain. The inversions of $A_{j}(s)$ and $B_{j}(s)$ in Equations 54 and 52 are simply derived using standard Laplace transform tables, e.g., (Spiegel 1965). Denoting the inversion of $A(s)$ by $\bar{A}$ $(t)$, the result for $A_{j}(s)$ is

$$
\bar{A}_{j}(t)=L^{-1}\left[A_{j}(s)\right]=\frac{q_{j}}{D\left(\alpha_{j}^{4}+C_{j}\right)}\left[1-\cos \left(a_{j} t\right)\right] j=1,2, \ldots
$$

The result for $B_{j}(s)$ follows directly from Equations 52 and 55

$$
\begin{aligned}
\bar{B}_{j}(t) & =L^{-1}\left[B_{j}(s)\right] \\
& =\frac{-p_{0} \alpha_{j}^{2}}{1+p_{1} \alpha_{j}^{2}} \frac{q_{j}}{D\left(\alpha_{j}^{4}+C_{j}\right)}\left[1-\cos \left(a_{j} t\right)\right] \\
j & =1,2, \ldots
\end{aligned}
$$

with Equations 55 and 56, the exact and explicit solutions for the transient problem can be expressed as

$$
\begin{aligned}
& w(r, t)=\sum_{j=1}^{\infty} \bar{A}_{j}(t) J_{0}\left(\alpha_{j} r\right) \\
& \phi(r, t)=\sum_{j=1}^{\infty} \bar{B}_{j}(t) J_{0}\left(\alpha_{j} r\right)
\end{aligned}
$$

The final solutions for the bending moments $M_{r}(r, t)$ and $M_{\theta}(r, t)$ are obtained introducing Equation 57 into Equations 32 and 33.

\section{Clamped circular plate}

The initial conditions and boundary conditions are

$$
\begin{array}{ll}
t=0: w=\dot{w}=\phi & =\dot{\phi}=0 . \\
r=a: & w=d w / d r=\phi, \\
z= \pm h: & \phi=0 \\
z= \pm\left(h+h_{1}\right): & \phi=0
\end{array}
$$

For the solution, we consider

$$
\begin{aligned}
w^{*}(r, s)= & \sum_{j=1}^{\infty} A_{j}^{\prime}(s) J_{0}\left(\alpha_{j} r\right)+C(s) \\
& \times\left(r^{2}-a^{2}\right), \quad \phi^{*}(r, s) \\
= & \sum_{j=1}^{\infty} B_{j}^{\prime}(s) J_{0}\left(\alpha_{j} r\right)
\end{aligned}
$$

where $A_{j}^{\prime}(s), B_{j}^{\prime}(s)$, and $C(s)$ are unknown functions and should be determined. Substituting $w^{\prime \prime}(r, s)$ and $\phi^{*}(r, s)$ into Equations 43 and 44 should satisfy

$$
\begin{aligned}
& A_{j}^{\prime}(s) \alpha_{j}^{4}-p_{0} \alpha_{j}^{2} B_{j}^{\prime}(s)+\lambda s^{2}\left[A_{j}^{\prime}(s)+C(s)\left(r^{2}-a^{2}\right)\right]=\frac{q_{j}}{s D} \\
& -p_{1} \alpha_{j}^{2} B_{j}^{\prime}(s)-B_{j}^{\prime}(s)+p_{2}\left[4 C(s)-\alpha_{j}^{2} A_{j}^{\prime}(s)\right]=0
\end{aligned}
$$

A supplementary expansion is presented as

$$
\begin{aligned}
\lambda\left(r^{2}-a^{2}\right) & =c_{1} J_{0}\left(\alpha_{1} r\right)+c_{2} J_{0}\left(\alpha_{2} r\right)+\ldots, \\
& =\sum_{j=1}^{\infty} c_{j} J_{0}\left(\alpha_{j} r\right)
\end{aligned}
$$

where $c_{j}$ is a constant and can be obtained by the orthogonality of Bessel functions as follows:

$$
c_{j}=\frac{2}{a^{2}} \frac{1}{J_{1}^{2}\left(\alpha_{j} a\right)} \int_{0}^{a} r\left(r^{2}-a^{2}\right) \lambda J_{0}\left(\alpha_{j} r\right) d r, j=1,2, \ldots
$$

It should be noted that the solutions $w^{\prime \prime}(r)$ and $\phi^{*}(r)$ in Equation 60 satisfy Equations 43 and 44 and all initial and boundary conditions in the problem, excluding $d w /$ $d r=0$ at $r=a$. Therefore, providing $C(s)$ is fixed to fulfill

$$
r=a: d w^{*} / d r=0
$$

where according to Equation 60, the solutions of the individual terms are

$$
2 C(s) a-\alpha_{j} J_{1}\left(\alpha_{j} a\right) A_{j}^{\prime}(s)=0 .
$$

Substituting $A_{j}^{\prime}(s)$ from Equation 66 into Equation 62 and a supplementary expansion $4=\sum_{j=1}^{\infty} \bar{q}_{j} J_{0}\left(\alpha_{j} r\right)$, one derives 
Table 1 Material properties of the piezoelectric coupled FGM plate (Ebrahimi and Rastgo 2008)

\begin{tabular}{ll}
\hline Property & Value \\
\hline Host FG plate & \\
$E_{\mathrm{c}}=205(\mathrm{GPa})$ & $\rho_{\mathrm{c}}=7,800\left(\mathrm{~kg} / \mathrm{m}^{3}\right)$ \\
$E_{\mathrm{m}}=200(\mathrm{GPa})$ & $\rho_{\mathrm{m}}=8,900\left(\mathrm{~kg} / \mathrm{m}^{3}\right)$ \\
$\mathrm{PZT}$ & \\
$C_{11}^{E}=132 \times 10^{9}$ & $C_{12}^{E}=71 \times 10^{9}$ \\
$C_{33}^{E}=115 \times 10^{9}$ & $C_{13}^{E}=73 \times 10^{9}$ \\
$\bar{C}_{11}^{E}=85.7 \times 10^{9}$ & $\bar{C}_{12}^{E}=24.7 \times 10^{9}$ \\
$e_{31}=-4.1\left(\mathrm{C} / \mathrm{m}^{2}\right)$ & $e_{33}=14.1\left(\mathrm{C} / \mathrm{m}^{2}\right)$ \\
& $\bar{e}_{31}=-13.05\left(\mathrm{C} / \mathrm{m}^{2}\right)$ \\
$\Xi_{11}=7.124 \times 10^{-9}(\mathrm{~F} / \mathrm{m})$ & $\Xi_{33}=5.841 \times 10^{-9}(\mathrm{~F} / \mathrm{m})$ \\
& $\rho_{2}=7,500\left(\mathrm{~kg} / \mathrm{m}^{3}\right)$ \\
\hline
\end{tabular}

$$
B_{j}^{\prime}(s)=\frac{p_{2} \alpha_{j}\left(\bar{q}_{j} J_{1}\left(\alpha_{j} a\right)-2 a \alpha_{j}\right)}{2 a\left(1+p_{1} \alpha_{j}^{2}\right)} A_{j}^{\prime}(s)
$$

where it is obtained by the orthogonality of the Bessel functions as follows:

$$
\bar{q}_{j}=\frac{8}{a \alpha_{j} J_{1}\left(\alpha_{j} a\right)}
$$

Substituting Equations 67 and 63 into Equation 61 gives

$$
A_{j}^{\prime}(s)=\frac{q_{j}}{D\left(\lambda+\frac{c_{j} \alpha_{j} J_{1}\left(\alpha_{j} a\right)}{2 a}\right)} \frac{1}{s D\left(s^{2}+\bar{a}_{j}^{2}\right)}
$$
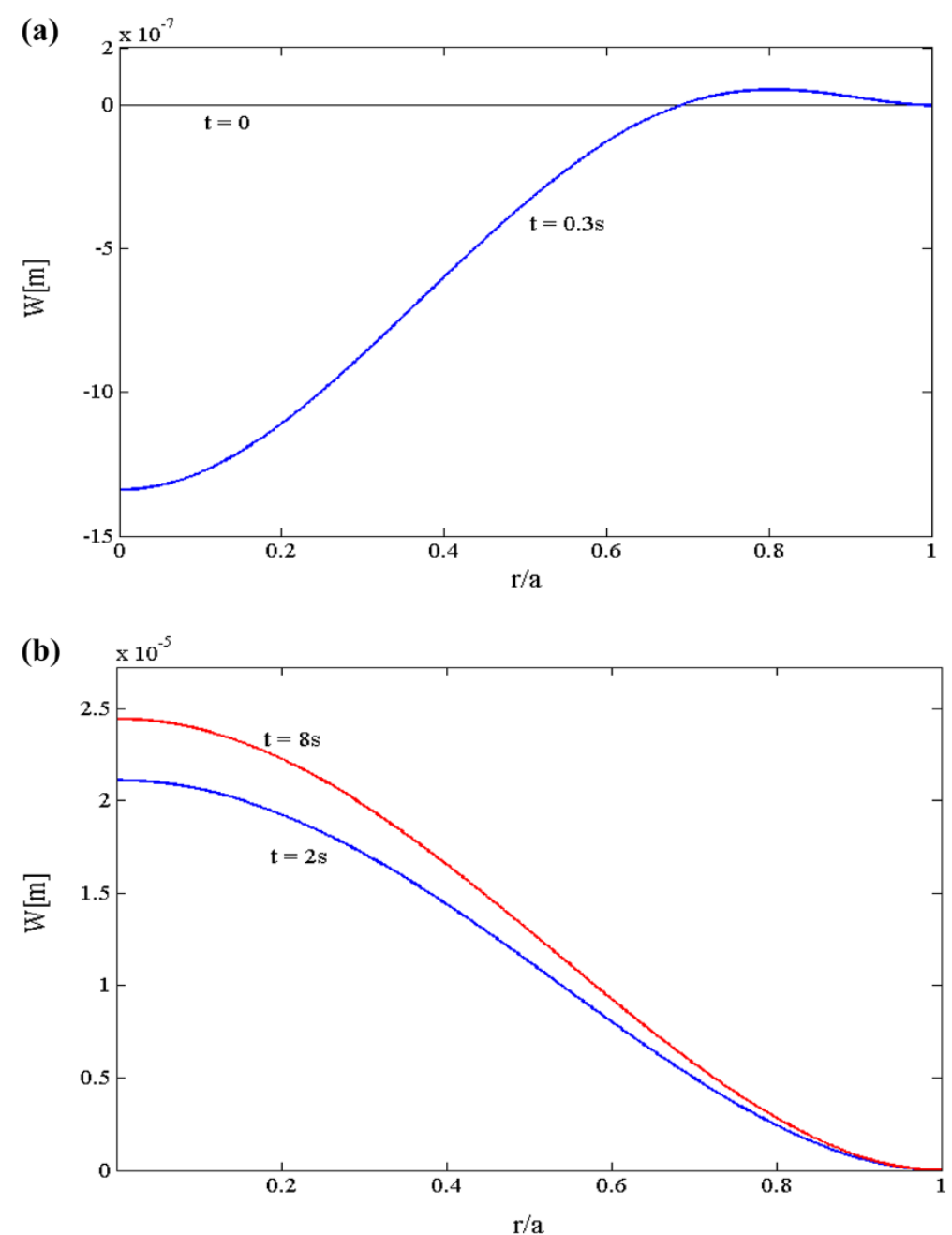

Figure 2 Radial distribution of deflection for clamped boundary condition. (a) Shortly after the application of the load and (b) later in time for $g=0$. 
with

$$
\bar{a}_{j}=\sqrt{\frac{\alpha_{j}^{4}-\beta_{j}}{\lambda+\frac{c_{j} \alpha_{j} J_{1}\left(\alpha_{j} a\right)}{2 a}}}, \quad \beta_{j}=\frac{p_{0} p_{2} \alpha_{j}^{3}\left(\bar{q}_{j} J_{1}\left(\alpha_{j} a\right)-2 a \alpha_{j}\right)}{2 a\left(1+p_{1} \alpha_{j}^{2}\right)},
$$

The inverse Laplace transform is applied to $w^{*}(r, s)$ and $\phi^{\prime \prime}(r, s)$ to derive the final solution in the time domain. The inversions of $A_{j}^{\prime}(s)$ and $B_{j}^{\prime}(s)$ in Equations 69 and 67 are simply derived using standard Laplace transform tables, e.g., (Spiegel 1965).

Representing the inversion of $A^{\prime}(s)$ by $\bar{A}^{\prime}(t)$, the result for $A_{j}^{\prime}(s)$ is

$$
\begin{aligned}
\bar{A}_{j}^{\prime}(t) & =L^{-1}\left[A_{j}^{\prime}(s)\right] \\
& =\frac{q_{j}}{D\left(\alpha_{j}^{4}-\beta_{j}\right)}\left[1-\cos \left(\bar{a}_{j} t\right)\right], j=1,2, \ldots \\
\bar{B}_{j}^{\prime}(t) & =L^{-1}\left[B_{j}^{\prime}(s)\right]=\frac{\beta_{j}}{\alpha_{j}^{2}} \frac{q_{j}}{D\left(\alpha_{j}^{4}-\beta_{j}\right)}\left[1-\cos \left(\bar{a}_{j} t\right)\right], j=1,2, \ldots
\end{aligned}
$$

The result for $C(s)$ follows directly from Equations 66 and 70

$$
C(t)=L^{-1}[C(s)]=\frac{1}{2 a} \sum_{j=1}^{\infty} \bar{A}^{\prime}{ }_{j}(t) \alpha_{j} J_{1}\left(\alpha_{j} a\right)
$$
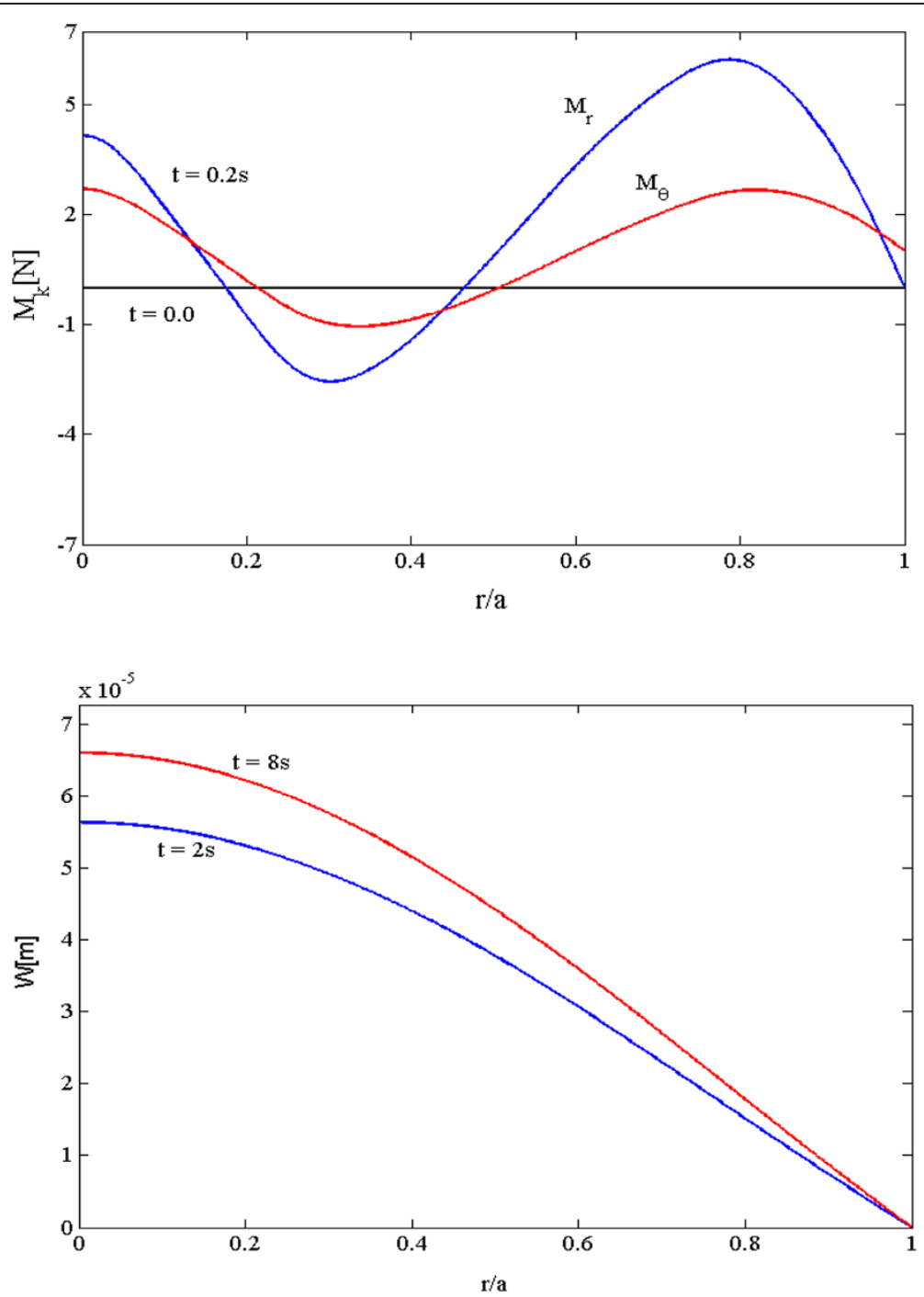

Figure 3 Radial distribution of bending moment (top) and deflection (bottom) for simply supported for $g=0$. 


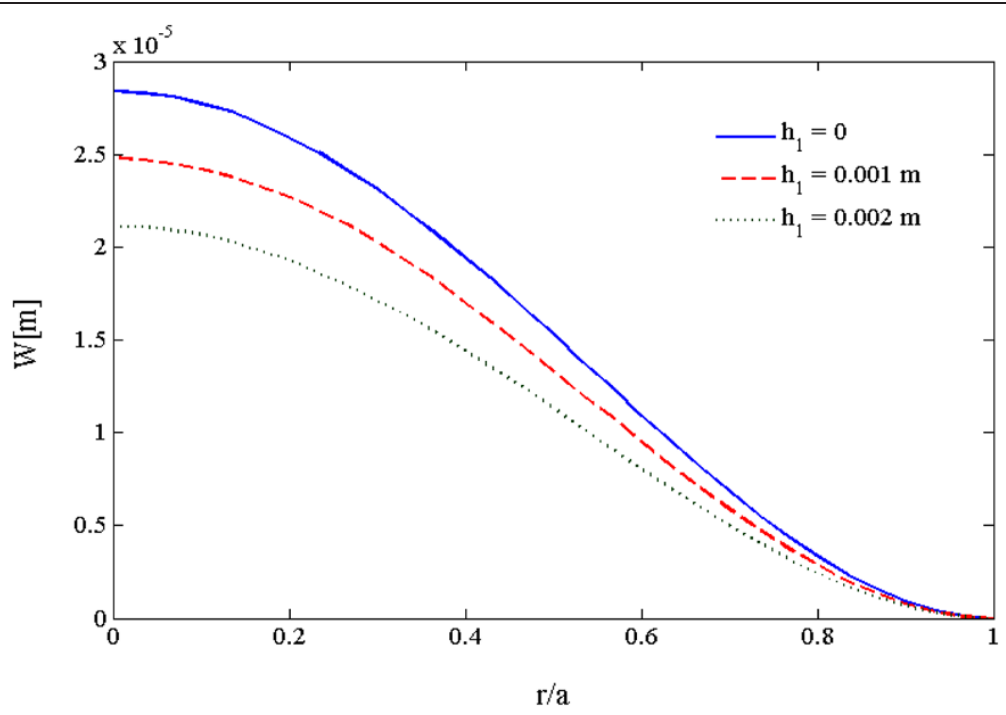

Figure 4 Effect of piezoelectric layer on radial deflection of FG plate for $g=2$ (clamped).

Note that for $j=1,2, \ldots, \beta_{j}$ is negative, and as a result, $\alpha_{j}^{4}-\beta_{j}^{4}$ in Equation 70 is always greater than zero, making $A_{j}^{\prime}$ always bounded.

With Equations 70, 71, and (72), the exact and explicit solutions for the transient problem can be expressed as

$$
\begin{aligned}
w(r, t) & =\sum_{j=1}^{\infty} \overline{A_{j}^{\prime}}(t) J_{0}\left(\alpha_{j} r\right)+C(t)\left(r^{2}-a^{2}\right) \\
\phi(r, t) & =\sum_{j=1}^{\infty} \overline{B_{j}^{\prime}}(t) J_{0}\left(\alpha_{j} r\right)
\end{aligned}
$$

\section{Results and discussion}

In this section, a set of case studies was considered to evaluate on the performance of the models on the transient analysis of FG three-layer circular plates. The geometric size and material parameters for the FG plate used in the numerical analysis are presented in Table 1 . In this example, the thickness ratio of the piezoelectric layer and main plate $\left(h_{1} / 2 h\right)$ is $1 / 10$. The radius of the circular plate is equal to $0.6 \mathrm{~m}$, and the thickness of the FG host is $0.01 \mathrm{~m}$; also, the external load equal to $1 \mathrm{kPa}$ is applied uniformly on the top of the piezoelectric layer.

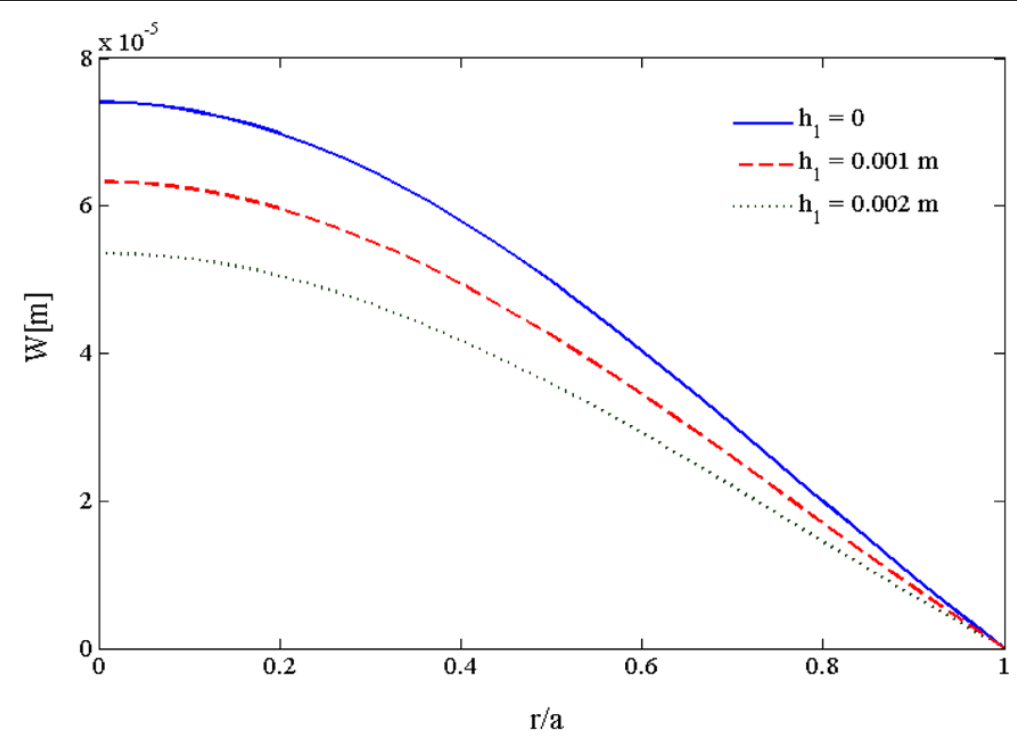

Figure 5 Effect of piezoelectric layer on radial deflection of FG plate for $g=2$ (simply supported). 


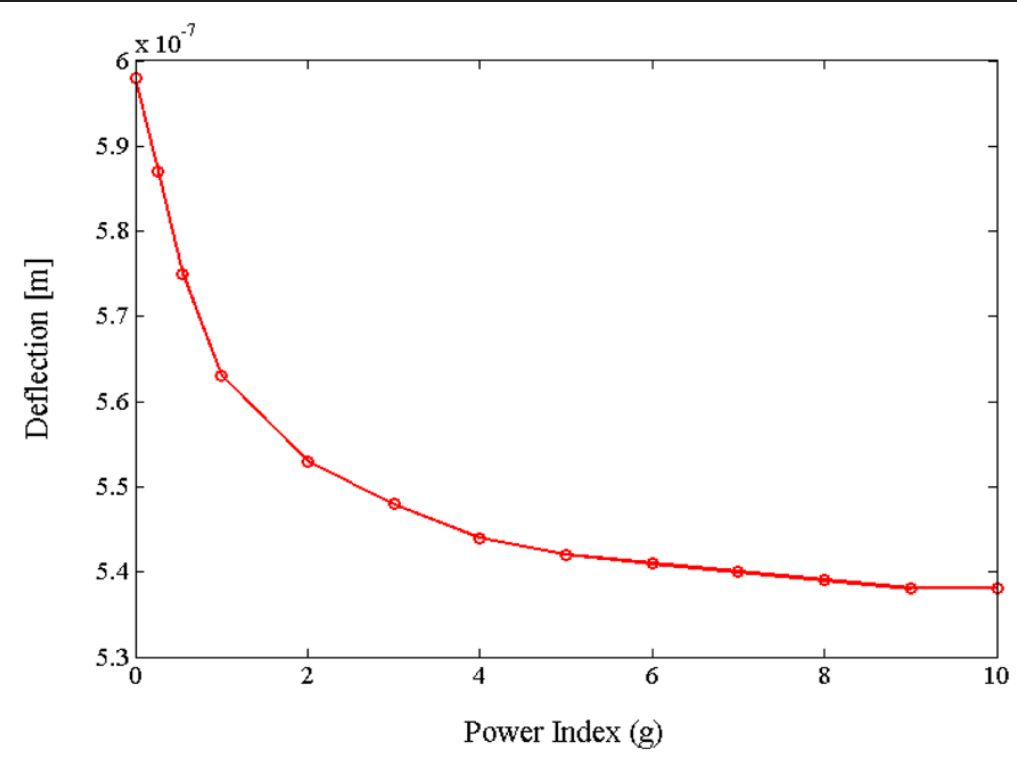

Figure 6 Effect of power index on the deflection of plate at $r=0$.

Figure 2 shows the radial distribution of the deflection of plate for $g=0$ and clamped boundary condition at different moments in time: briefly after applying the uniform load, Figure 2a, and later in time. The curves in Figure 2 show that the initial conditions (59) and boundary conditions at $r=0: d w / d r=0$ and at $r=a: w=d w / d r=0$ are satisfied.

Also, Figure 3 shows the radial distribution of bending moment of plate for $g=0$ and simply supported boundary condition at different moments in time. The curves shows that the initial conditions (40) and boundary conditions at $r=a: w=M_{r}=0$ are satisfied. These results demonstrate that the newly developed solution is numerically stable and enables the calculation of the plate characteristics anywhere within the plate and for small as well as large times.

Figures 4 and 5 show the radial deflection of piezoelectric FG structure for piezoelectric layers with difference thickness for clamped and simply supported boundary conditions at $t=2 \mathrm{~s}$. It is noticeable that by increasing the value of $h_{1}$, the deflection of plate decreases under the same value of transverse load. Also, it can be observed that by increasing the value of piezoelectric layers from 0 to $0.001 \mathrm{~m}$, the deflection of the compound plate decreases by approximately $14 \%$ and that by increasing from 0 to $0.002 \mathrm{~m}$, the deflection of the compound plate decreases by approximately $28 \%$ for both boundary conditions.

Also, Figure 6 shows the center deflection of piezo-FG plate at time $t=0.2 \mathrm{~s}$ for different values of $g$ under the same value of mechanical load. As seen from Figure 6, the deflection of the piezo-plate decreases by increasing $g$. This is due to the fact that higher values of power law index $g$ correspond to high portion of ceramic in comparison with the metal part, thus making such FG plate less flexible. The highest values for deflection are obtained for full metal
Table 2 The first three mode resonance frequencies $(\mathrm{Hz})$ for piezo-FG plate for various values of power index

\begin{tabular}{|c|c|c|c|c|c|}
\hline $\begin{array}{l}\text { Power } \\
\text { index (g) }\end{array}$ & $\begin{array}{c}\text { Mode } \\
\text { number }\end{array}$ & $\begin{array}{c}\text { Present } \\
(\mathrm{Hz})\end{array}$ & $\begin{array}{l}\text { (Ebrahimi and } \\
\text { Rastgo 2008) }\end{array}$ & $\begin{array}{c}\text { Difference } \\
(\%)\end{array}$ & $\begin{array}{c}\text { (Wang et al. } \\
\text { 2001) }\end{array}$ \\
\hline \multirow[t]{3}{*}{0} & 1 & 69.37 & 69.52 & 0.22 & 69.33 \\
\hline & 2 & 418.99 & 417.86 & 0.27 & 418.03 \\
\hline & 3 & 1029.74 & 1039 & -0.9 & $1,038.2$ \\
\hline \multirow[t]{3}{*}{1} & 1 & 67.51 & 67.88 & -0.55 & - \\
\hline & 2 & 408.38 & 406.83 & 0.38 & - \\
\hline & 3 & $1,003.65$ & $1,001.51$ & 0.21 & - \\
\hline \multirow[t]{3}{*}{3} & 1 & 66.49 & 67.07 & -0.87 & - \\
\hline & 2 & 403.01 & 402.23 & 0.19 & - \\
\hline & 3 & 990.45 & 983.5 & 0.19 & - \\
\hline \multirow[t]{3}{*}{5} & 1 & 66.17 & 66.81 & -0.97 & - \\
\hline & 2 & 401.33 & 400.71 & 0.15 & - \\
\hline & 3 & 986.33 & 982.2 & 0.42 & - \\
\hline \multirow[t]{3}{*}{7} & 1 & 66.02 & 66.72 & -1.06 & - \\
\hline & 2 & 400.55 & 397.32 & 0.81 & - \\
\hline & 3 & 984.42 & 980.4 & 0.41 & - \\
\hline \multirow[t]{3}{*}{9} & 1 & 65.94 & 66.61 & -1.02 & - \\
\hline & 2 & 400.12 & 396.81 & 0.83 & - \\
\hline & 3 & 983.36 & 979.02 & 0.44 & - \\
\hline \multirow[t]{3}{*}{10} & 1 & 65.91 & 66.59 & -1.03 & - \\
\hline & 2 & 399.67 & 396.5 & 0.79 & - \\
\hline & 3 & 982.98 & 978.1 & 0.5 & - \\
\hline
\end{tabular}




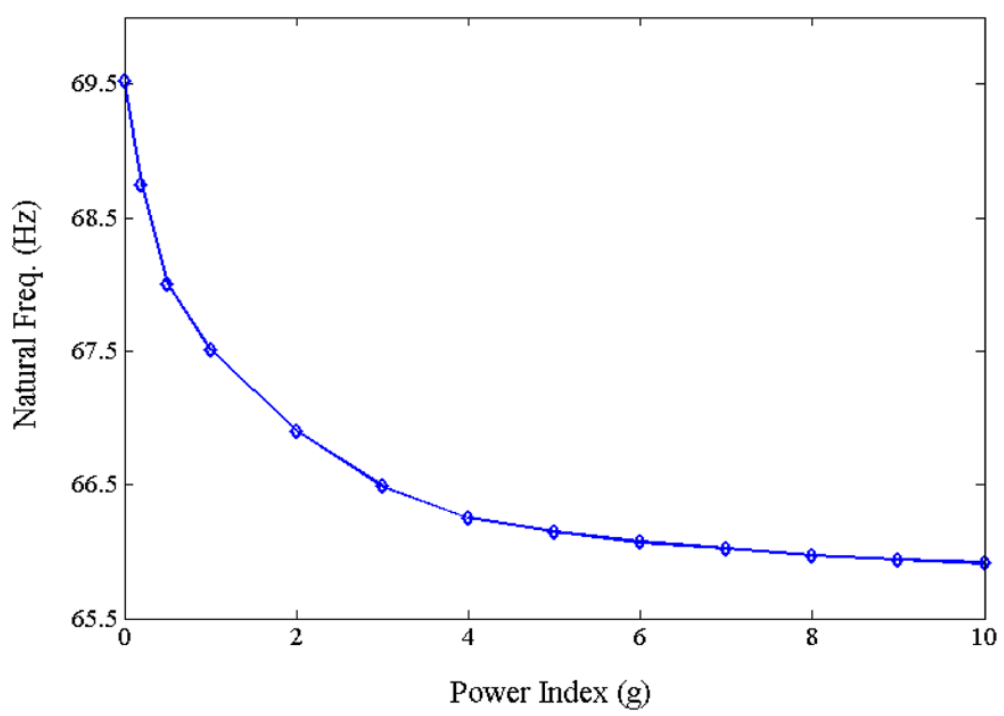

Figure 7 Effect of power index on the natural frequency (first mode).

plate $(g=0)$, while the lowest deflection is obtained for full ceramic plate $(g \rightarrow \infty)$. This is because an increase in the value of the power law index results in an increase in the value of elasticity modulus. In other words, the host plate becomes less flexible as the power law index increases. It can be seen that the deflection of the system decreases by increasing $g$ and stabilizes for $g$ values greater than 7. In fact, for $g>>1$, the FGM plate becomes a ceramic plate and the compound plate transforms into a laminated plate with ceramic core as a main plate.

Note that when a dynamic system is suddenly subjected to nonperiodic excitation force $F(t)$, the response of the system is called transient response. Transient oscillations occur with the natural frequency of the system, and its extent depends on the type of stimulation. In a spring-mass system or a continuous system, when the system is stimulated by a step function, the response is as follows (Loja et al. 2012):

$$
w(x, t)=G F_{0} \cdot\left(1-\cos \left(\omega_{j} t\right)\right)
$$

where $G$ is a coefficient, and $\omega_{j}$ is the natural frequency of the system. The comparison between the above equation and Equation 55 shows that $a_{j}=\omega_{j}$ (i.e., $\omega_{j}=a_{j}=\sqrt{\frac{\alpha_{j}^{4}+C_{j}}{\lambda}}$, where, in this study, $\omega_{j}$ is the axsymmetric natural frequency of the system. By calculating $a_{j}$, the axsymmetric natural frequencies of the system are obtained. Table 2 shows the first three axisymmetric natural frequencies of piezo-FG plate for different values of $g$. The obtained results in Table 2 indicate that by increasing the value of $g$, the frequency of the system decreases. In order to see better the effect of $g$ variations on the natural frequency of the different plates, Figure 7 also illustrates these variations for the first-mode shape.
As seen from Figure 7, the natural frequencies of the system decrease as $g$ increases and stabilized $g$ values greater than 7. In fact, for $g>>1$, the FGM plate becomes a ceramic plate, and the compound plate transforms into a laminated plate with ceramic core as $s$ host plate. This decreasing trend of natural frequency for smaller values of $g$ is more pronounced, for example, by increasing the value of $g$ from 1 to 3 (approximately 200\%), the frequency of the first mode for the compound plate decreases by $1.32 \%$ but by increasing g from 3 to 9 (approximately 200\%) of the same plate and for the same mode, the frequency decreases by $0.71 \%$. Table 3 shows the effect of the piezoelectric layer on the natural frequency of the system. As seen from this table, by increasing the piezoelectric layer, the natural frequency increases and the piezo-effect is more obvious when there is a thicker piezoelectric layer on the main plate.

\section{Conclusion}

In this paper, the transient bending of a three-layer piezoelectric circular FG plate based on the Kirchhoff plate theory is studied. The material properties of the FG plate are assumed to vary through the thickness of the plate based on the power law distribution. Also the distribution of electric potential in the piezoelectric layers follows a

Table 3 Effect of piezoelectric layer on resonance frequencies

\begin{tabular}{lccc}
\hline Thickness ratio & First mode & Second mode & Third mode \\
\hline $1 / 12$ & 68.65 & 417.62 & $1,026.62$ \\
$1 / 10$ & 69.52 & 418.99 & $1,029.74$ \\
$1 / 8$ & 71.52 & 420.96 & $1,034.82$ \\
$1 / 5$ & 73.68 & 428.44 & $1,052.90$ \\
\hline
\end{tabular}


quadratic function in short circuited form. The solution is presented in terms of elementary Bessel functions and analytical inverse Laplace transforms. The solution enables the efficient determination of the plate characteristics anywhere within the plate for small as well as large times with reliable precision. It can be observed that the power index $(g)$ has significant effect on the deflection amplitude and natural frequency of the piezo-FG plate. It is shown that the thickness of the piezo-layer has significant effect on the deflection amplitude and natural frequency of the piezo-FG plate.

\section{Competing interests}

The authors declare that they have no competing interests.

\section{Authors' contributions}

AAJ carried out the analytical solution, AA and OR conceived of the study, and participated in its design and coordination. All authors read and approved the final manuscript.

\section{Author details}

${ }^{1}$ Faculty of Mechanical Engineering, K.N.Toosi University of Technology, Pardis St., Tehran 19697, Iran. ${ }^{2}$ Smart Structures and New Advanced Materials Laboratory, Mechanical Engineering Department, University of Zanjan, Zanjan 45371-38791, Iran.

Received: 24 February 2014 Accepted: 1 July 2014

\section{Published online: 16 September 2014}

\section{References}

Abramowitz, M, \& Stegun, IA. (1964). Handbook of Mathematical Functions: With Formulars, Graphs, and Mathematical Tables (Vol. 55). New York: Courier Dover Publications.

Alibeigloo, A. (2010). Thermoelasticity analysis of functionally graded beam with integrated surface piezoelectric layers. Composite Structures, 92(6), 1535-1543.

Batra, R, \& Geng, T. (2002). Comparison of active constrained layer damping by using extension and shear mode piezoceramic actuators. Journal of Intelligent Material Systems and Structures, 13(6), 349-367.

Batra, R, \& Liang, X. (1997). The vibration of a rectangular laminated elastic plate with embedded piezoelectric sensors and actuators. Computers \& Structures, 63(2), 203-216

Behjat, B, \& Khoshravan, M. (2012). Geometrically nonlinear static and free vibration analysis of functionally graded piezoelectric plates. Composite Structures, 94(3), 874-882.

Bhangale, RK, \& Ganesan, N. (2006). Static analysis of simply supported functionally graded and layered magneto-electro-elastic plates. International Journal of Solids and Structures, 43(10), 3230-3253.

Bian, Z, Lim, C, \& Chen, W. (2006). On functionally graded beams with integrated surface piezoelectric layers. Composite Structures, 72(3), 339-351.

Ebrahimi, F, \& Rastgo, A. (2008). An analytical study on the free vibration of smart circular thin FGM plate based on classical plate theory. Thin-Walled Structures, 46(12), 1402-1408.

Ebrahimi, F, \& Rastgoo, A. (2008). Free vibration analysis of smart annular FGM plates integrated with piezoelectric layers. Smart Materials and Structures, 17(1), 015044

Ebrahimi, F, Rastgoo, A, \& Kargarnovin, M. (2008). Analytical investigation on axisymmetric free vibrations of moderately thick circular functionally graded plate integrated with piezoelectric layers. Journal of Mechanical Science and Technology, 22(6), 1058-1072.

Ebrahimi, F, Rastgoo, A, \& Atai, A. (2009). A theoretical analysis of smart moderately thick shear deformable annular functionally graded plate. European Journal of Mechanics-A/Solids, 28(5), 962-973.

Es'haghi, M, Hashemi, SH, \& Fadaee, M. (2011). Vibration analysis of piezoelectric FGM sensors using an accurate method. International Journal of Mechanical Sciences, 53(8), 585-594.

Fakhari, V, Ohadi, A, \& Yousefian, P. (2011). Nonlinear free and forced vibration behavior of functionally graded plate with piezoelectric layers in thermal environment. Composite Structures, 93(9), 2310-2321.
Hashemi, SH, Khorshidi, K, Es'haghi, M, Fadaee, M, \& Karimi, M. (2012). On the effects of coupling between in-plane and out-of-plane vibrating modes of smart functionally graded circular/annular plates. Applied Mathematical Modelling, 36(3), 1132-1147.

$\mathrm{He}$, X, Ng, T, Sivashanker, S, \& Liew, K. (2001). Active control of FGM plates with integrated piezoelectric sensors and actuators. International Journal of Solids and Structures, 38(9), 1641-1655.

Hosseini Hashemi, S, Es'haghi, M, \& Karimi, M. (2010). Closed-form vibration analysis of thick annular functionally graded plates with integrated piezoelectric layers. International Journal of Mechanical Sciences, 52(3), 410-428

Hosseini-Hashemi, S, Es'haghi, M, \& Rokni Damavandi Taher, H. (2010a). An exact analytical solution for freely vibrating piezoelectric coupled circular/annular thick plates using Reddy plate theory. Composite Structures, 92(6), 1333-1351.

Hosseini-Hashemi, S, Es'haghi, M, Rokni Damavandi Taher, H, \& Fadaie, M. (2010b). Exact closed-form frequency equations for thick circular plates using a thirdorder shear deformation theory. Journal of Sound and Vibration, 329(16), 3382-3396

Huang, X-L, \& Shen, H-S. (2006). Vibration and dynamic response of functionally graded plates with piezoelectric actuators in thermal environments. Journal of Sound and Vibration, 289(1), 25-53.

Jandaghian, A, Jafari, A, \& Rahmani, O. (2013). Exact solution for Transient bending of a circular plate integrated with piezoelectric layers. Applied Mathematical Modelling, 37(12), 7154-7163.

Jandaghian, A, Jafari, A, \& Rahmani, O. (2014). Vibrational response of functionally graded circular plate integrated with piezoelectric layers: An exact solution. Engineering Solid Mechanics, 2(2), 119-130.

Kargarnovin, M, Najafizadeh, M, \& Viliani, N. (2007). Vibration control of a functionally graded material plate patched with piezoelectric actuators and sensors under a constant electric charge. Smart Materials and Structures, 16(4), 1252

Komeili, A, Akbarzadeh, AH, Doroushi, A, \& Eslami, MR. (2011). Static analysis of functionally graded piezoelectric beams under thermo-electro-mechanical loads. Advances in Mechanical Engineering, 2011, 1-10.

Li, X, Ding, H, \& Chen, W. (2008). Three-dimensional analytical solution for functionally graded magneto-electro-elastic circular plates subjected to uniform load. Composite Structures, 83(4), 381-390.

Liew, K, He, X, Ng, T, \& Kitipornchai, S. (2002). Active control of FGM shells subjected to a temperature gradient via piezoelectric sensor/actuator patches. International Journal for Numerical Methods in Engineering, 55(6), 653-668

Liew, K, He, X, Ng, T, \& Kitipornchai, S. (2003). Finite element piezothermoelasticity analysis and the active control of FGM plates with integrated piezoelectric sensors and actuators. Computational Mechanics, 31(3-4), 350-358.

Loja, M, Soares, M, \& Barbosa, J. (2013). Analysis of functionally graded sandwich plate structures with piezoelectric skins, using B-spline finite strip method. Composite Structures, 96, 606-615.

Ootao, Y, \& Tanigawa, Y. (2000). Three-dimensional transient piezothermoelasticity in functionally graded rectangular plate bonded to a piezoelectric plate. International Journal of Solids and Structures, 37(32), 4377-4401.

Pan, E, \& Han, F. (2005). Exact solution for functionally graded and layered magneto-electro-elastic plates. International Journal of Engineering Science, 43(3), 321-339

Rahmani, O, \& Noroozi Moghaddam, MH. (2014). On the Vibrational Behavior of Piezoelectric Nano-Beams. Advanced Materials Research, 829, 790-794.

Rahmani, O, \& Pedram, O. (2014). Analysis and modeling the size effect on vibration of functionally graded nanobeams based on nonlocal Timoshenko beam theory. International Journal of Engineering Science, 77, 55-70.

Rahmani, O, Malekzadeh, K, \& Khalili, SMR. (2010). Analytical Solution for Free Vibration of Sandwich Structures with a Functionally Graded Syntactic Foam Core. Materials Science Forum, 636, 1143-1149.

Rao, SS. (2007). Vibration of continuous systems. New Jersey: John Wiley \& Sons

Ray, M, \& Batra, R. (2007). Vertically reinforced 1-3 piezoelectric composites for active damping of functionally graded plates. AlAA Journal, 45(7), 1779-1784.

Ray, M, \& Sachade, H. (2006). Finite element analysis of smart functionally graded plates. International Journal of Solids and Structures, 43(18), 5468-5484.

Reddy, J, \& Cheng, Z-Q. (2001). Three-dimensional solutions of smart functionally graded plates. Journal of Applied Mechanics, 68(2), 234-241. 
Shen, H-S. (2005). Postbuckling of FGM plates with piezoelectric actuators under thermo-electro-mechanical loadings. International Journal of Solids and Structures, 42(23), 6101-6121.

Shiyekar, S, \& Kant, T. (2010). An electromechanical higher order model for piezoelectric functionally graded plates. International Journal of Mechanics and Materials in Design, 6(2), 163-174.

Sneddon, IN. (1995). Fourier transforms. New York: Courier Dover Publications. Spiegel, MR. (1965). Laplace transforms. New York: McGraw-Hill.

Tanigawa, Y. (2001). Control of the transient thermoelastic displacement of a functionally graded rectangular plate bonded to a piezoelectric plate due to nonuniform heating. Acta Mechanica, 148(1-4), 17-33.

Timoshenko, S, Woinowsky-Krieger, S, \& Woinowsky, S. (1959). Theory of plates and shells, vol 2. New York: McGraw-hill.

Vel, SS, \& Batra, R. (2001). Exact solution for rectangular sandwich plates with embedded piezoelectric shear actuators. AlAA Journal, 39(7), 1363-1373.

Wang, B, \& Noda, N. (2001). Design of a smart functionally graded thermopiezoelectric composite structure. Smart Materials and Structures, 10(2), 189.

Wang, Q, Quek, S, Sun, C, \& Liu, X. (2001). Analysis of piezoelectric coupled circular plate. Smart Materials and Structures, 10(2), 229

Zhang, X, Veidt, M, \& Kitipornchai, S. (2004). Transient bending of a piezoelectric circular plate. International Journal of Mechanical Sciences, 46(12), 1845-1859.

doi:10.1186/s40712-014-0008-5

Cite this article as: Jafari et al.: Transient bending analysis of a

functionally graded circular plate with integrated surface piezoelectric

layers. International Journal of Mechanical and Materials Engineering 2014 1:8.

\section{Submit your manuscript to a SpringerOpen ${ }^{\circ}$ journal and benefit from:}

- Convenient online submission

- Rigorous peer review

- Immediate publication on acceptance

- Open access: articles freely available online

- High visibility within the field

- Retaining the copyright to your article

Submit your next manuscript at $\gg$ springeropen.com 